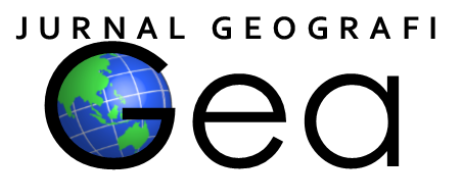

\title{
ANALISIS STABILITAS LERENG PADA PELAPUKAN BATUAN VULKANIK DI CIKALONGWETAN KABUPATEN BANDUNG BARAT JAWA BARAT
}

\author{
Muhammad Azhar Fareka1, Nandang R. Sutarto' ${ }^{2}$, Totok Doyo Pamungkas ${ }^{3}$ \\ ${ }^{1,2}$ Jurusan Teknologi Geologi, Politeknik Geologi dan Pertambangan AGP \\ ${ }^{3}$ Program Studi Pendidikan Geografi, Fakultas Pendidikan Ilmu Pengetahuan Sosial, \\ Universitas Pendidikan Indonesia \\ 1azharfareka11@gmail.com, ${ }^{2}$ totokdp@upi.edu
}

\begin{abstract}
The location of the investigation is located in the Cikalong Wetan area, West Bandung Regency, West Java. 6 41 '30 "- 6 "44' '30" LS and $107^{\circ} 26^{\prime}$ ' $30^{\prime \prime}-107^{\circ} 29^{\prime}$ '00" East with an area of $\pm 6 \mathrm{~km}^{2}$. The purpose of this investigation is to determine the value of the slope safety factor (Fs) in weathering volcanic rocks and provide technical recommendations in efforts to prevent and prevent soil movement. The method of investigation is carried out by means of field investigations, testing of soil mechanics laboratory, literature study to obtain information / data on soil movements and observations of soil movements in the area of investigation. The slope stability analysis was calculated using the Slope/w program from Geostudio 2007 software. The results of slope stability analysis at 3 locations with different slope, showed that location 1 slope $35^{\circ}$ and location 2 slope $65^{\circ}$ under wet or saturated soil conditions obtained Safety Factor (Fs) location 1 with a value of 0.626 and location 2 value, 0.367 less than 1.25 means that the slope is normal / frequent ground motion or unstable slopes, but different at location 3 with a slope of $25^{\circ}$ obtained a Safety Factor (Fs) of 1.430 which means that more than 1.25 the ground movement is rarely stable or the slope is stable. Whereas in dry / unsaturated soil conditions, locations 1 and 2 obtained a Safety Factor value (Fs) of 0.680 location 1 and location 2 obtained with a value of 0.404 which means less than 1.07 slopes remained unstable, but location 3 on dry soil conditions Safety Factor (Fs) 1,450 over 1.25 means that the slope is stable.
\end{abstract}

Keywords: Stability, slope, safety factor.

\begin{abstract}
ABSTRAK
Lokasi penyelidikan terletak di daerah Cikalong Wetan, Kabupaten Bandung Barat, Jawa Barat. 6 41'30" - 6 $6^{\circ} 44^{\prime} 30^{\prime}$ ' LS dan $107^{\circ} 26^{\prime} 30^{\prime}$ - $107^{\circ} 29^{\prime} 00^{\prime}$ ' BT dengan luas \pm 6 $\mathrm{km}^{2}$. Tujuan dari penyelidikan ini untuk mengetahui nilai faktor kemanan lereng (Fs) pada pelapukan batuan vulkanik dan memberikan rekomendasi teknis dalam upaya penanggulangan dan pencegahan gerakan tanah. Metode penyelidikan dilakukan dengan cara penyelidikan lapangan, mengujian labolatorium mekanika tanah, studi pustaka untuk mendapatkan informasi/data gerakan tanah serta pengamatan gerakan tanah di daerah penyelidikan. Analisis stabilitas lereng di hitung menggunakan program Slope/w dari software Geostudio 2007. Hasil analisis stabilitas lereng pada 3 lokasi dengan kemiringan berbeda, menunjukan bahwa lokasi 1 kemiringan lereng $35^{\circ}$ dan lokasi 2 kemiringan lereng $65^{\circ}$ pada kondisi tanah basah atau jenuh air didapat Faktor Keamanan (Fs) lokasi
\end{abstract}


1 dengan nilai 0,626 dan lokasi 2 dengan nilai 0,367 kurang dari 1,25 artinya lereng biasa/sering terjadi gerakan tanah atau lereng labil, namun berbedapada lokasi 3 dengan kemiringan lereng $25^{\circ}$ didapat Faktor Keamanan (Fs) 1,430 yang artinya lebih dari 1,25 jarang terjadi gerakan tanah atau lereng stabil. Sedangkan pada kondisi tanah kering / tidak jenuh air, dilokasi 1 dan 2 didapat nilai Faktor Keamanan (Fs) 0,680 lokasi 1 dan lokasi 2 didapat dengan nilai 0,404 yang artinya kurang dari 1,07 lereng masih tetap labil, namun dilokasi 3 pada kondisi tanah kering Faktor Keamanan (Fs) 1,450 lebih dari 1,25 artinya lereng stabil.

Kata kunci: Kestabilan, lereng, faktor keamanan.

\section{PENDAHULUAN}

Permukaan tanah tidak selalu membentuk bidang datar akan tetapi selalu mempunyai perbedaan elevasi antara tempat yang satu dengan yang lainnya sehingga membentuk suatu lereng (slope). Perbedaan elevasi tersebut pada kondisi tertentu dapat menimbulkan kelongsoran lereng sehingga dibutuhkan suatu analisis stabilitas lereng. Analisis stabilitas lereng mempunyai peran yang sangat penting pada perencanaan konstruksi-konstruksi sipil. Kondisi tanah asli tidak selalu sesuai dengan perencanaan yang diinginkan, misalnya lereng yang membutuhkan timbunan dan lain sebagainya. Analisis stabilitas lereng diperlukan agar diperoleh konstruksi lereng yang mantap sesuai dengan syarat keamanan.

Daerah penyelidikan, secara umum merupakan daerah perbukitan, dengan batuan penyusun berupa batuan vulkanik dengan pelapukan yang cukup tebal.

Cikalong Wetan termasuk daerah rawan gerakan tanah berdasarkan kondisi tersebut, untuk mengantisipasi terjadi gerakan tanah yang akan mengakibatkan korban jiwa, harta, dan menggangu pengguna jalan maka dilakukan penyelidikan kestabilan lereng dengan cara menganalisa kemiringan lereng untuk mengetahui faktor keamanannya (Fs) yang mungkin akan terjadi gerakan tanah di sepanjang jalur jalan tersebut.

Maksud dari penyelidikan ini adalah untuk mengetahui nilai faktor keamanan (Fs) suatu lereng di Cikalongwetan dengan cara melakukan pengamatan, pengukuran dan pengambilan sempel tanah terganggu (DS) maupun tak terganggu (UDS).

Tujuan dari penyelidikan ini adalah untuk mengetahui nilai faktor keamanan lereng di daerah Cikalong Wetan dan sekitarnya. nilai faktor keamanan lereng tersebut dapat digunakan sebagai acuan perencanaan pembagunan infrastruktur, serta sebagai informasi untuk meningkatkan kewaspadaan masyarakat terhadap kemungkinan terjadinya gerakan tanah di daerah sekitar, sehingga dapat memperkecil/mengurangi kerusakan sarana dan prasarana pembangunan, serta korban jiwa manusia.

Ruang lingkup pembahasan dibatasi antara lain dengan uraian sebagai berikut:

1) Menghitung perbedaan faktor keamanan lereng pada sudut lereng yang berbeda dengan menggunakan metoda program Slope/w.

2) Merekomendasikan cara penanggulangan gerakan tanah

\section{METODE PENELITIAN}

Metode penelitian dilakukan dengan cara penyelidikan lapangan dan studi pustaka laporan-laporan terdahulu dengan rincian sebagai berikut:

\section{Studi Pustaka}

1) Mempelajari data sekunder berupa laporan-laporan pemeriksaan bencana gerakan tanah yang terdapat di daerah penyelidikan, dari literatur kepustakaan maupun dari internet.

2) Mempelajari data curah hujan bulanan atau tahunan daerah penyelidikan.

3) Mempelajari peta topografi, peta geologi dan peta curah hujan daerah penyelidikan.

4) Mempelajari teori analisis stabilitas lereng.

\section{Pengumpulan Data}

Data yang digunakan untuk menunjang penyelidikan ini antara lain:

1) Peta dasar berupa peta rupa bumi digital Indonesia, lembar 1209-242 Cikalongwetan, skala 1:25.000. 
2) Peta geologi lembar Cianjur, Jawa, oleh Sudjatmiko 1:100.000.

3) Peta rata-rata curah hujan tahunan periode 1981-2010 di DKI Jakarta, Banten dan geofisika (BMKG).

4) Beberapa laporan hasil pemeriksaan gerakan tanah di daerah penyelidikan oleh Pusat Sumber Daya Air Tanah dan Geologi Lingkungan, Pusat Vulkanologi dan Mitigasi Bencana Geologi.

Untuk mendapatkan informasi/data gerakan tanah serta pengamatan gerakan tanah didaerah penyelidikan, maka detail kegiatan selama penelitian diuraikan sebagai berikut:

1. Penyelidikan lapangan, meliputi:

- Observasi Morfologi (kemiringan lereng dan bentuk lereng).

- Pengamatan Geologi.

- Pengamatan tata guna lahan.

- Pengukuran dimensi lereng (sudut lereng, panjang lereng, elevasi), sebanyak 3 lokasi.

- Pengambilan sampel terganggu (6 buah), dan tak terganggu ( 6 buah).

2. Penelitian laboratorium untuk mengetahui:

- Karakteristik berat - volume.

- Karakteristik plastisitas.

- Karakteristik distribusi butir.

- Karakteristik kekuatan tanah.

Untuk menganalisis faktor kestabilan lereng digunakan program Slope/w. Program Slope/w merupakan bagian dari aplikasi GEOSTUDIO 2007. Tahap awal pemograman yaitu membuat model dari lereng yang diselidiki sedang parameter tanah didapat dari pengujian laboratorium sampel tanah yang diambil dari lapangan.

Program Slope/w adalah suatu program untuk menganalisis stabilital lereng. Program Slope/w dapat menganalis permasalahan lereng sederhana maupun masalah yang kompleks untuk berbagai bentuk busur, sifat tanah, metode analisis dan kondisi pembebanan.

\section{KONDISI UMUM DAERAH PENYELIDIKAN \\ Morfologi dan Kemiringan Lereng}

Sebagai besar daerah penyelidikan merupakan daerah perbukitan bergelombang curam yang menempati bagian utara dan selatan dari daerah penyelidikan, sedangkan daerah lainnya berupa perbukitan landai menempati bagian tengah daerah penyelidikan.

Pola aliran sungai yang berkembang didaerah penyelidikan umumnya membentuk pola airan sungai paralel yang menempati bagian selatan daerah penyelidikan. Pola aliran sungai tersebut ditentukan berdasarkan interpretasi dari peta Rupa Bumi Indonesia lembar Cikalong Wetan skala 1:25.000.

Secara garis besar morfologi daerah penyelidikan dapat dibagi menjadi beberapa satuan, yang setiap satuan mempunyai ciri dan kenampakan yang khas baik dari bentuk topografinya, kemiringan lereng maupun pola alirannya.

Berdasarkan klasifikasinya kemiringan lereng dan satuan morfologi menurut Van Zuidam (1985) (Tabel 1, Klasifikasi Geomorfologi Menurut Van Zuidam), Maka dengan mengelompokkan garis kontur yang berpola relatif sama pada peta topografi, kemudian ditarik garis tegak lurus kontur dan dihitung kemiringan lerengnya dengan menggunakan persamaan sebagai berikut:

$$
\mathbf{S}=\frac{(n-1) x I c}{d} X 100 \%
$$

Keterangan:

$\mathrm{S}=$ kemiringan lereng $(\%)$

Ic $=$ interval kontur (meter)

$\mathrm{d}=$ jarak sebenarnya (meter)

$\mathrm{n}=$ jumlah kontur yang terpotong

Bentuk bentang alam dan sudut lereng daerah penyelidikan termasuk dalam 2 (dua) satuan morfologi, seperti terlihat dalam tabel 1

1. Perbukitan bergelombang curam

2. Satuan morfologi perbukitan landai. 
Tabel 1. Klasifikasi kemiringan lereng dan satuan morfologi

\begin{tabular}{|c|l|}
\hline Kemiringan Lereng & \multicolumn{1}{|c|}{ Satuan Morfologi } \\
\hline $0^{\circ}-2^{\circ}(0-2 \%)$ & Pedataran \\
\hline $2^{\circ}-4^{\circ}(2-7 \%)$ & Perbukitan landai $\checkmark$ \\
\hline $4^{\circ}-8^{\circ}(7-15 \%)$ & Perbukitan bergelombang \\
\hline $8^{\circ}-16^{\circ}(15-30 \%)$ & Perbukitan bergelombang curam $\checkmark$ \\
\hline $16^{\circ}-35^{\circ}(30-70 \%)$ & Perbukitan curam \\
\hline $35^{\circ}-55^{\circ}(70-140 \%)$ & Perbukitan sangat curam \\
\hline$>55^{\circ}(>140 \%)$ & Perbukitan tergak/terjal \\
\hline
\end{tabular}

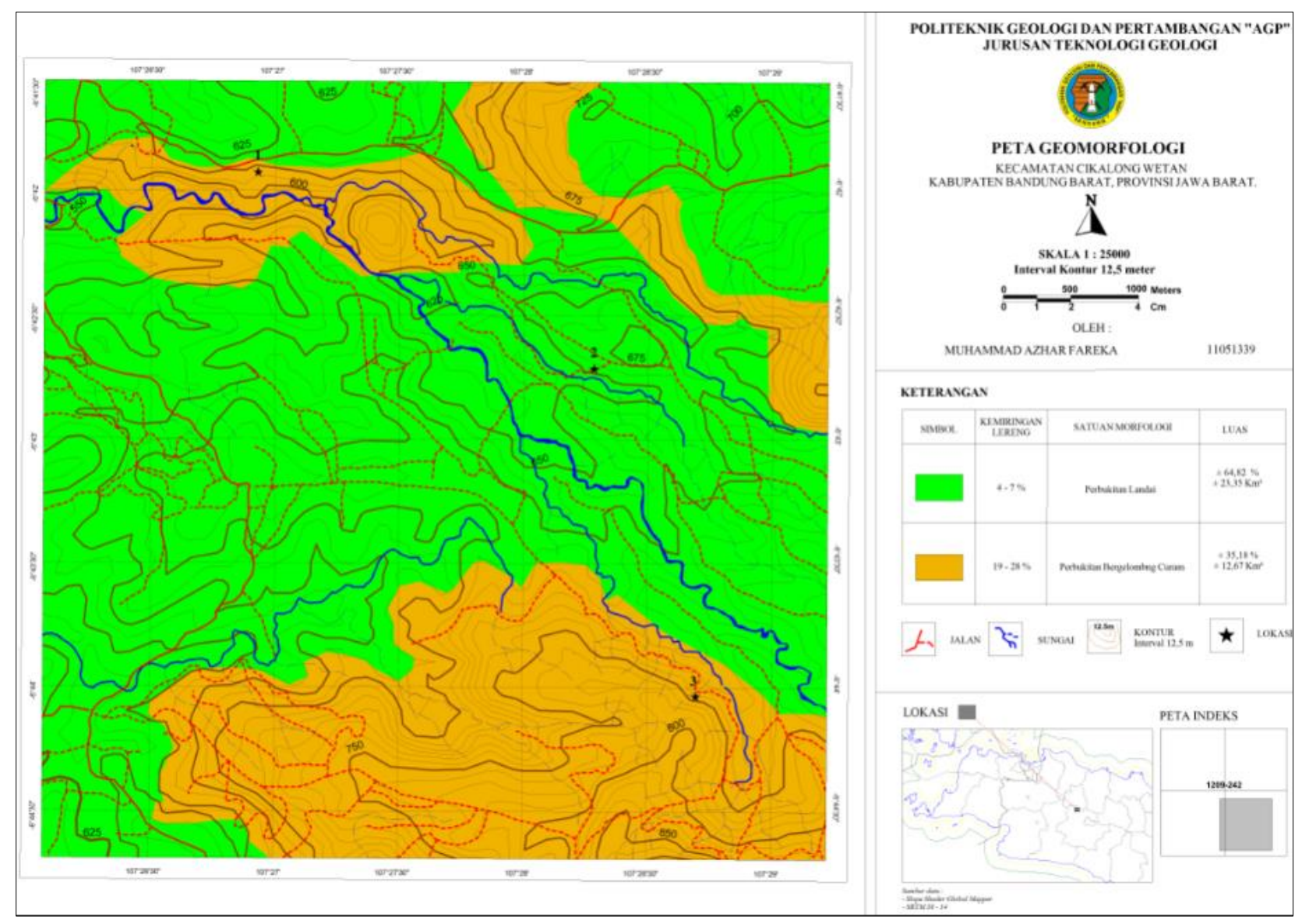

Gambar 1. Peta Geomorfologi

\section{Pola Aliran Sungai}

Pola aliran sungai yang berkembang di daerah penyelidikan umumnya membentuk pola aliran sungai denritik, yaitu aliran sungai yang mana mempunyai banyak anak cabang yang menjuru ke segala arah lalu berkontribusi membentuk menyerupai ranting pohon yang akhirnya bermuara kesungai induk. Pola aliran sungai ini mengikuti kemiringan lereng dengan tipe bebatuan homogen dan berada pada lembah berbentuk V. pola aliran sungai ini menyebabkan terjadinya gerakan tanah apabila terjadi hujan yang lebat dan aliran air yang menjadi deras bisa menyerang bagian kaki- kaki lereng sehingga bertambah curam, bila dibiarkan terus menerus,

Aliran sungai daerah penyelidikan di bagian timur mengalir ke sungai barat menuju Waduk Jatiluhur dan Waduk Cirata berdasarkan interpretasi dari peta Rupa Bumi Indonesia Lembar Cikalong Wetan skala 1:25.000. 


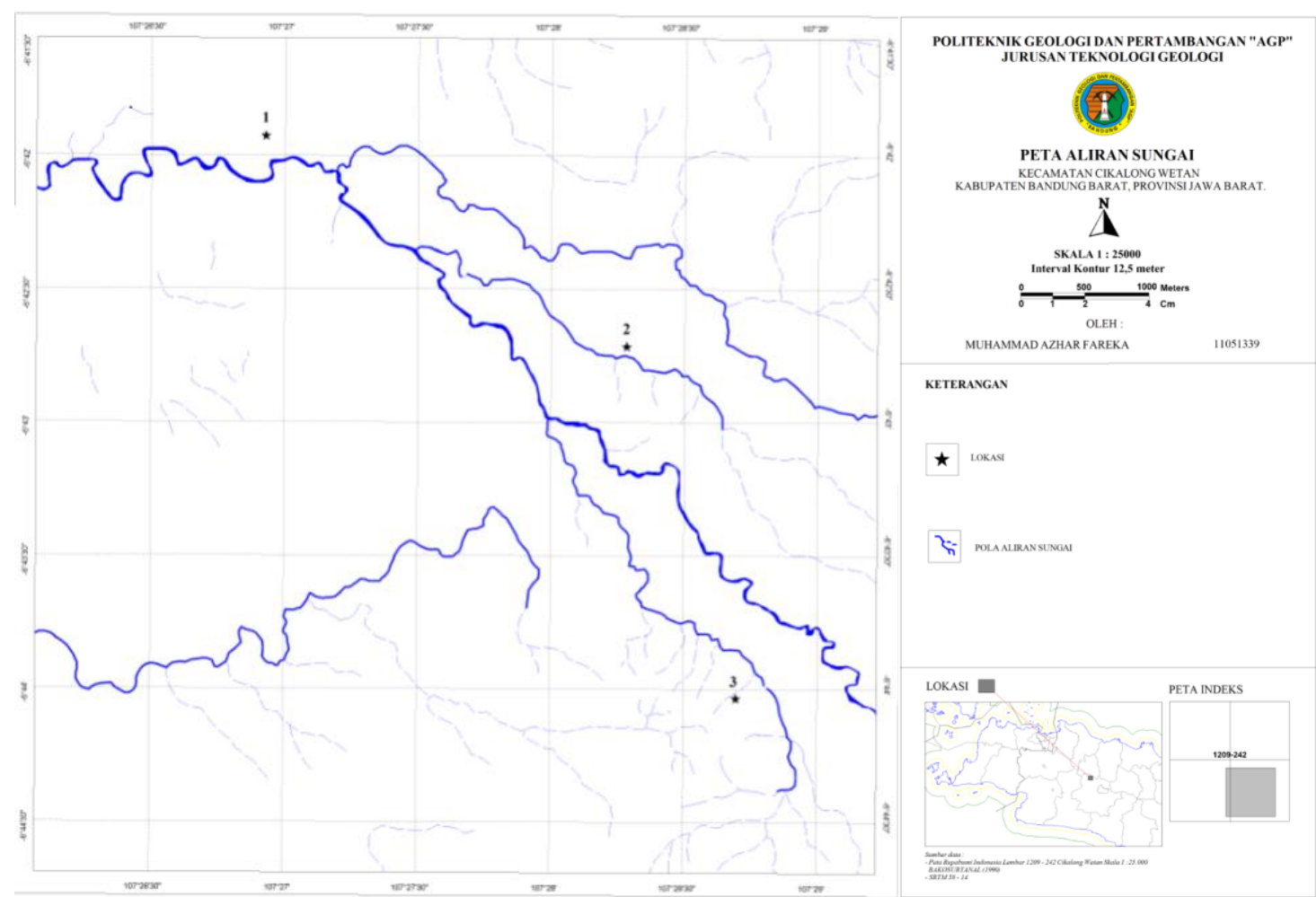

Gambar 2. Peta Aliran Sungai

\section{Batuan dan Tanah Pelapukan} Batuan

Penamaan dan pengelompokan satuan batuan dari daerah penyelidikan berdasarkan pada peta Geologi Lembar Cianjur skala 1:100.000 yang disusun oleh Sudjatmiko (1972). Sedangkan deskripsi tentang sifat fisik batuan dan tanah pelapukan berdasarkan hasil pengamatan lapangan dan data analisis laboratorium mekanika tanah dan batuan dari laporan terdahulu.

Susunan Stratigrafi daerah penyelidikan terdiri dari 1 satuan batuan, yaitu: Gunung Api Tua (QOB), terdiri dari Breksi vulkanik, lahar, lava, breksi gunung api, breksi aliran, endapan lahar, dan lava tebal $( \pm 0-150 \mathrm{~m})$.
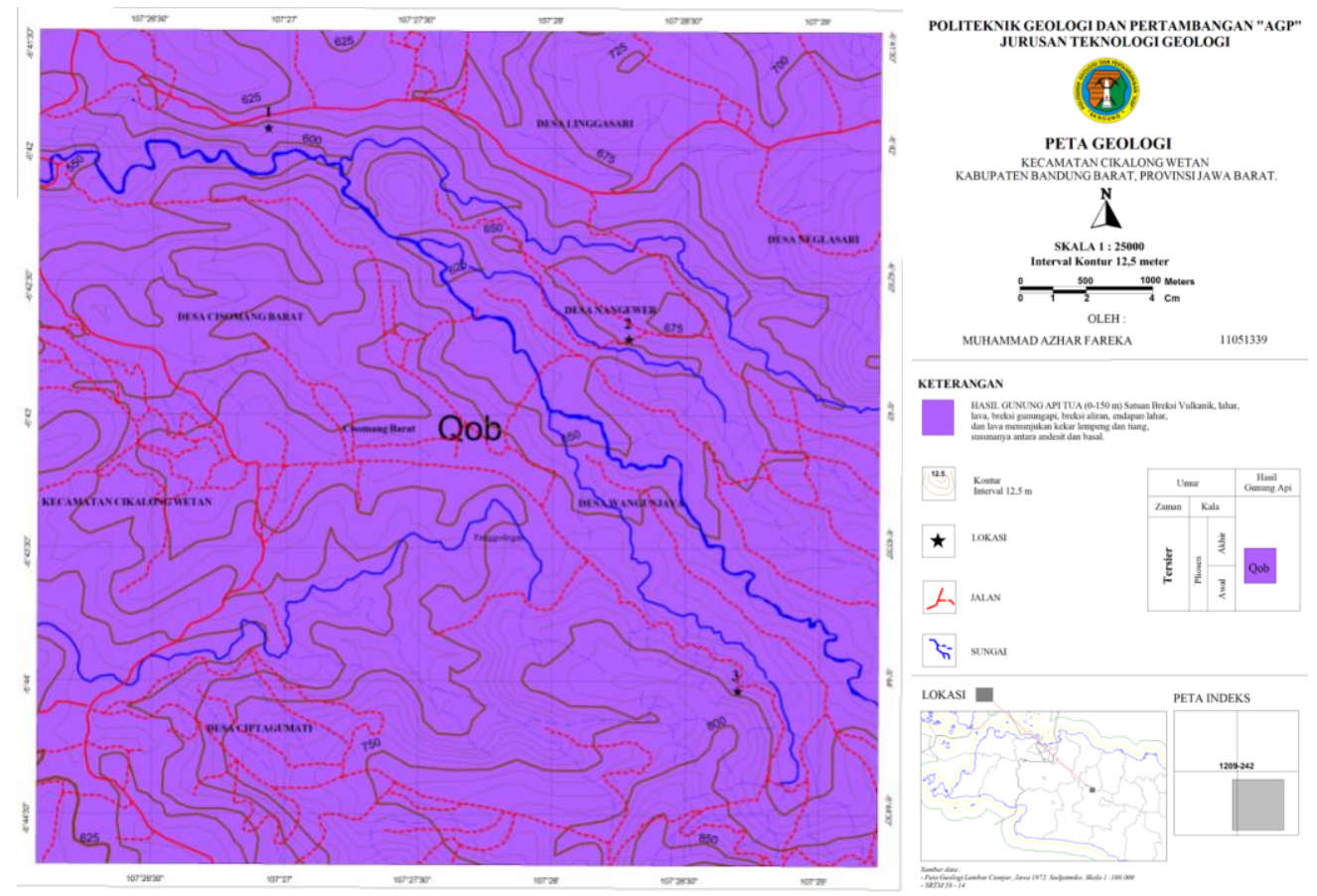

Gambar 3. Peta Geologi 


\section{Tanah Pelapukan}

Berdasarakan hasil penyelidikan dilapangan dan didukung dengan analisa laboratorium mekanika tanah, karakteristik jenis tanah keseluruhan di daerah penyelidikan adalah lanau-pasiran. (Sumber Peta Geologi Teknik Lembar Jawa Bagian Barat. Joni Sutisna dan Wahjono).
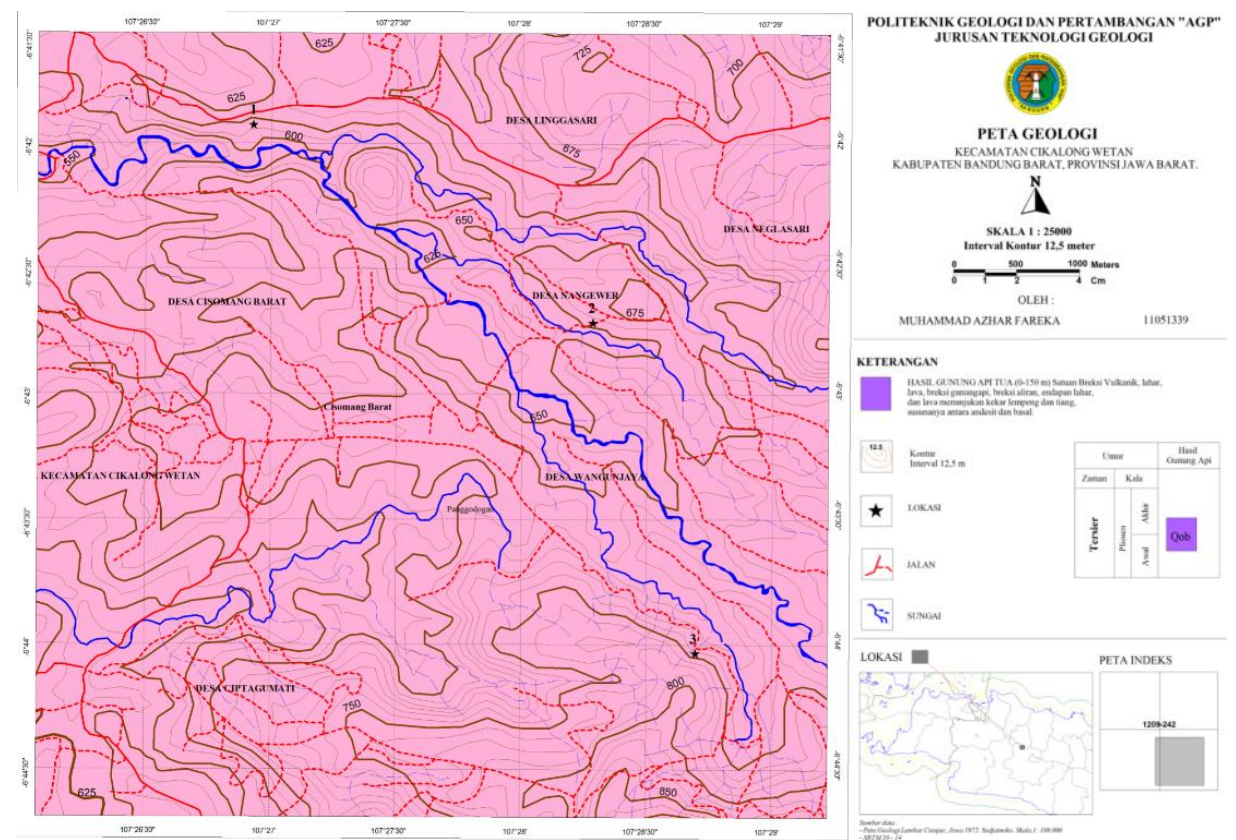

Gambar 4. Peta Tanah Lapukan

\section{Zona Gerakan Tanah}

Zona kerentanan gerakan tanah sangat rendah, rendah, menengah, dan zona kerentanan gerakan tanah tinggi. Tiga titik lokasi penyelidikan berada pada zona kerentanan gerakan tanah menengah dan zona gerakan tanah tinggi.
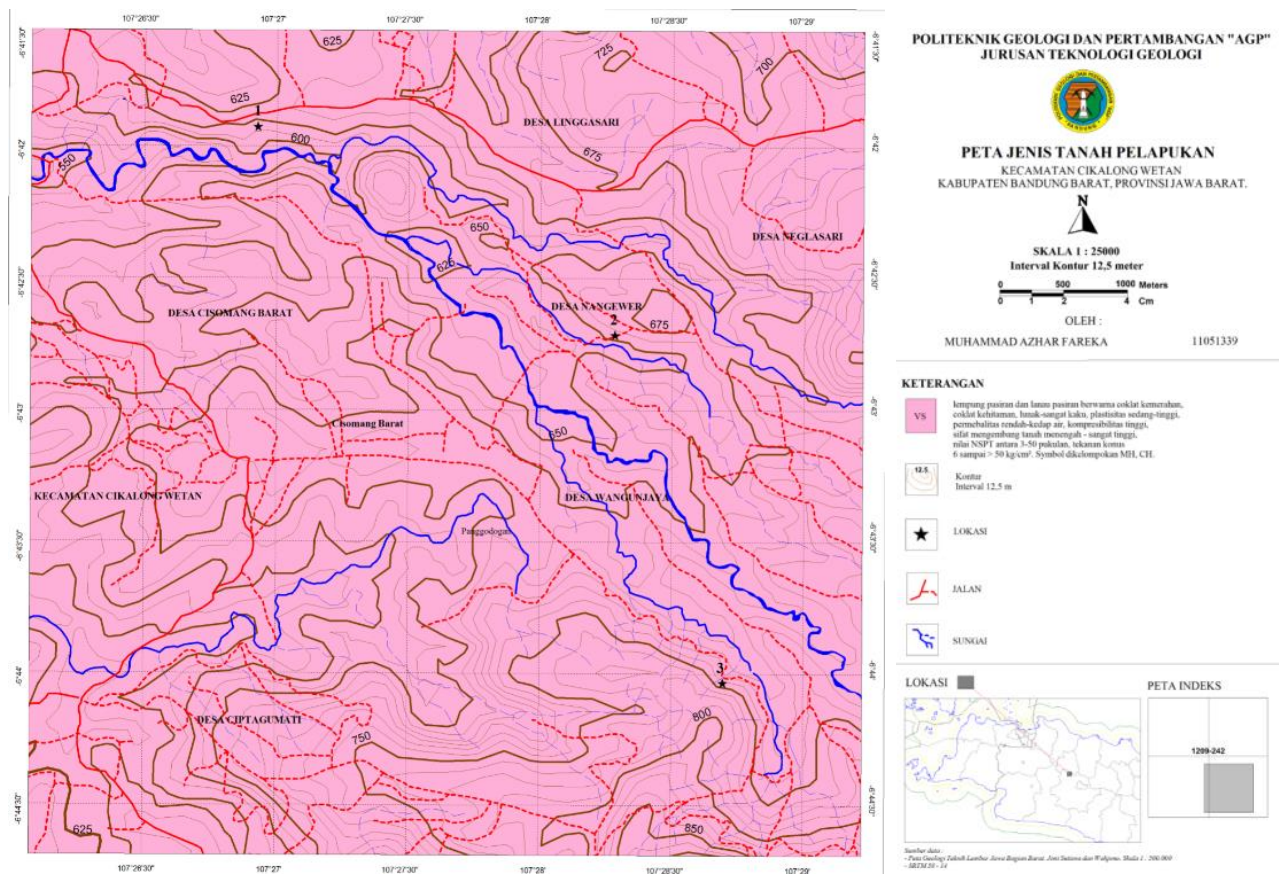

Gambar 5. Peta Zona Gerakan Tanah 


\section{Curah hujan dan Keairan}

Curah hujan rata-rata perbulan didaerah penyelidikan dari tahun 2013-2014 (gambar 6), menunjukan bahwa curah hujan di daerah penyelidikan mempunyai curah hujan relatif tinggi. Pada bulan kering dimulai bulan Juni sampai bulan September yang mempunyai kisaran curah hujan 10 $\mathrm{mm} /$ bulan sampai $90 \mathrm{~mm} /$ bulan dan bulan basah Oktober sampai bulan Mei mulai 100 $\mathrm{mm} /$ bulan sampai $325 \mathrm{~mm} /$ bulan.

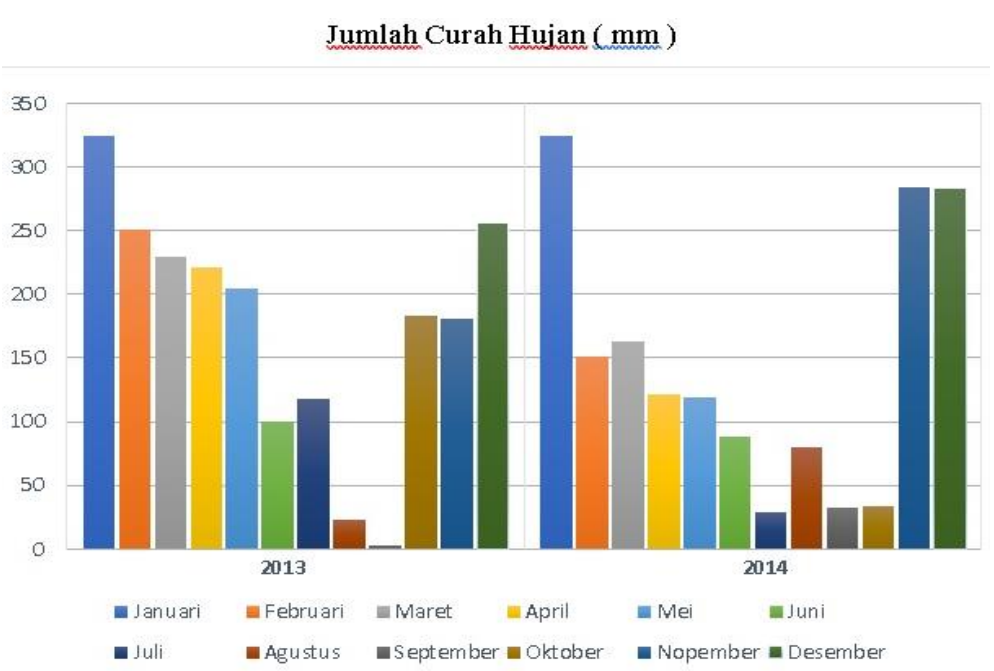

Sumber: Badan Meteorologi Klimatologi dan Geofisika (BMKG) Provinsi Jawa Barat

Gambar 6. Grafik curah hujan bulanan daerah penyelidikan tahunan 2013 - 2014

Pelaksanaan penyelidikian dilapangan dilaksanakan pada bulan November 2018 dan bulan November termasuk bulan basah, tetapi didaerah penyelidikan banyak terdapat gerakan tanah dilereng dekat aliran sungai, diarea gawir gerakan tanah lama dan lokasi yang dianalisa. Gerakan tanah biasanya terjadi pada bulan basah yaitu bulan Januari karena itensitas hujan sangat tinggi $325 \mathrm{~mm} /$ bulan.

Adapun evaluasi menurut F.H schmidit UMA Ferguson (1975), tentang evaluasi curah hujan kuantitatif besarnya curah hujan bulanan terhadap peresapan air kedalam tanah adalah sebagai berikut tabel 2.

Tabel 2. Hubungan kuantitas curah hujan bulanan terhadap peresapan air ke dalam tanah

\begin{tabular}{cc}
\hline $\begin{array}{c}\text { Besarnya curah hujan } \\
\text { bulanan }(\mathrm{mm})\end{array}$ & $\begin{array}{c}\text { Kemungkinan meresapnya air kedalam } \\
\text { lapisan tanah }\end{array}$ \\
\hline$<60$ & Semua menguap \\
$60-100$ & Hanya membasahi tanah \\
$>100$ & Dapat meresap kedalam tanah \\
\hline
\end{tabular}

\section{Tata Guna Lahan}

Berdasarkan Peta Tata Guna Lahan penggunaan lahan di daerah penyelidikan umumnya berupa kebun/perkebunan, ladang/tegalan, sawah, pemukiman.
Gerakan tanah umumnya banyak terjadi di tata guna lahan persawahan, kebun/perkebunan, ladang/tegalan dan lereng-lereng yang dekat dengan permukiman warga karena dibawah jalan raya seperti pada lokasi 1,2 , dan 3 . 


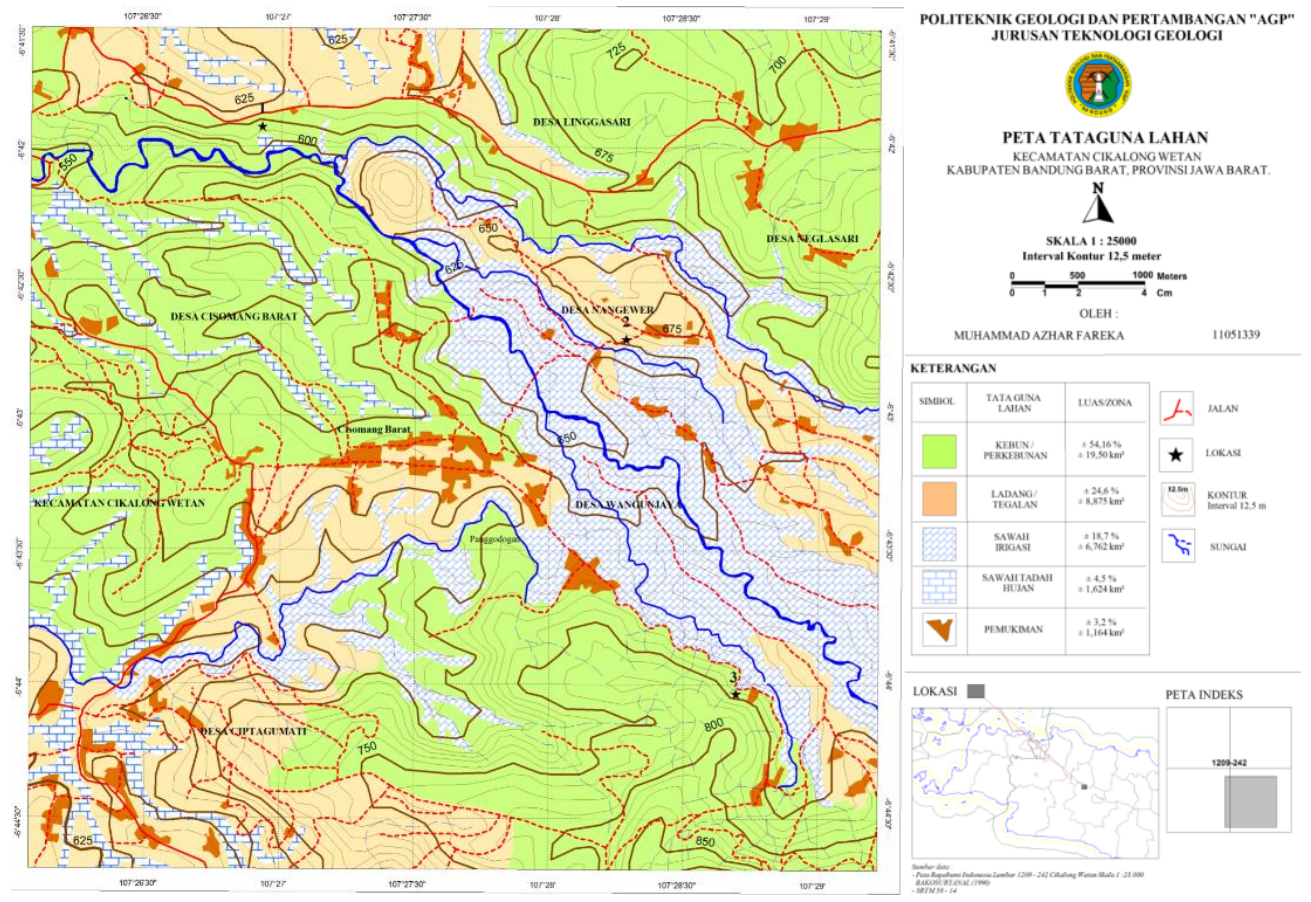

Gambar 7. Peta Tata Guna Lahan

\section{HASIL DAN PEMBAHASAN}

\section{Analisa Stabilitas Lereng}

Gerakan tanah yang paling sering dijumpai dilokasi penyelidikan yaitu gerakan tanah rotasi. Gerakan tanah ini adalah suatu gerakan yang relatif lambat dari suatu blok batuan, tanah ataupun campuran keduanya, sepanjang bidang gelincir yang berbentuk suatu busur lingkaran. Pada kondisi tanah homogen, bidang gelincir yang terjadi umunya berbentuk suatu busur lingkaran, tetapi dalam kenyataannya tidak seluruh bidang geser yang terjadi berupa suatu busur lingkaran akibat adanya sesar, lapisan lembek, dan faktor-faktor lainnya.

Pada analisis stabilitas lereng pemahaman mengenai faktor keamanan sangat penting. Faktor keamanan sangat dipengaruhi oleh kekuatan tanah. Dari hasil studi-studi menyeluruh tentang keruntuhan lereng menunjukkan bahwa, nilai faktor keamanan sebagai berikut.

Tabel 3. Nilai Faktor Kemanan berdasarkan frekuensi kejadian

\begin{tabular}{cc}
\hline Faktor Keamanan (Fs) & Kejadian \\
\hline Fs kurang dari 1,07 & $\begin{array}{c}\text { Gerakan Tanah biasa/sering terjadi } \\
\text { (Lereng Labil) }\end{array}$ \\
Fs antara 1,07 - 1,25 & $\begin{array}{c}\text { Gerakan Tanah pernah terjadi } \\
\text { (Lereng Kritis) } \\
\text { Fs diatas 1,25 } \\
\text { Gerakan Tanah jarang terjadi } \\
\text { (Lereng Stabil) }\end{array}$ \\
\hline & Sumber: Joseph E. Bowles, 1991
\end{tabular}

Analisis stabilitas lereng di hitung menggunakan Software GeoStudio 2007 dengan program Slope/w, parameter yang dimasukan ke program Slope/w di material model pilih Mohr-Coulomb dan di isikan Berat isi $(\gamma)$, Kohesi (c), dan Sudut geser $(\Phi)$. 
Tabel 4. Nilai konversi satuan $\gamma, \mathrm{c}, \Phi$ dan rata-rata

\begin{tabular}{|c|c|c|c|c|c|c|c|c|}
\hline Lokasi & $\begin{array}{l}\text { Tabung } \\
\text { Sampel }\end{array}$ & $\begin{array}{c}\text { Sudut } \\
\text { Lereng } \\
\alpha\end{array}$ & $\mathrm{t} / \mathrm{m}^{3}$ & $\begin{array}{c}\text { Berat } \\
\text { Isi } \\
\text { Jenuh } \\
\mathrm{KN} / \mathrm{m}^{3}\end{array}$ & $\begin{array}{l}\text { Rata - } \\
\text { Rata } \\
\text { KN/m }\end{array}$ & $\mathrm{t} / \mathrm{m}^{3}$ & $\begin{array}{c}\text { Berat } \\
\text { Isi } \\
\text { Kering } \\
\mathrm{KN} / \mathrm{m}^{3}\end{array}$ & $\begin{array}{c}\text { Rata - } \\
\text { Rata } \\
\mathrm{KN} / \mathrm{m}^{3}\end{array}$ \\
\hline \multirow{2}{*}{1} & A & \multirow{2}{*}{35} & 1.929 & 18.92 & \multirow{2}{*}{18.92} & 1.516 & 14,87 & \multirow{2}{*}{14.87} \\
\hline & B & & 1.930 & 18.93 & & 1.517 & 14.88 & \\
\hline \multirow{2}{*}{2} & A & \multirow{2}{*}{65} & 1.927 & 18.98 & \multirow{2}{*}{18.99} & 1.518 & 14.89 & \multirow{2}{*}{15.02} \\
\hline & B & & 1.938 & 19.00 & & 1.545 & 15.15 & \\
\hline \multirow{2}{*}{3} & A & \multirow{2}{*}{25} & 1.911 & 18.74 & \multirow{2}{*}{18.75} & 1.480 & 14.51 & \multirow{2}{*}{14.74} \\
\hline & B & & 1.914 & 18.77 & & 1.528 & 14.98 & \\
\hline
\end{tabular}

\begin{tabular}{|c|c|c|c|c|c|}
\hline $\mathrm{kg} / \mathrm{cm}^{2}$ & Kohesi & $\begin{array}{c}\text { Rata - Rata } \\
\text { Kpa }\end{array}$ & deg & $\begin{array}{c}\text { Sudut } \\
\text { Geser } \\
\Phi^{\mathbf{o}}\end{array}$ & $\begin{array}{c}\text { Rata - Rata } \\
\Phi^{\circ}\end{array}$ \\
\hline 0.146 & 14.32 & \multirow{2}{*}{13.68} & 15.30 & 15.3 & \multirow{2}{*}{17.9} \\
\hline 0.133 & 13.04 & & 20.50 & 20.5 & \\
\hline 0.190 & 18.63 & \multirow{2}{*}{17.8} & 21.30 & 21.3 & \multirow{2}{*}{21.8} \\
\hline 0.175 & 17.16 & & 22.30 & 22.3 & \\
\hline 0.120 & 11.77 & \multirow{2}{*}{9.82} & 22.80 & 22.8 & \multirow{2}{*}{34.2} \\
\hline 0.081 & 7.94 & & 22.80 & 22.8 & \\
\hline
\end{tabular}

Dalam setiap perhitungan (cara manual maupun cara komputer), semua satuan tiap-tiap variabel harus di perhatikan, seperti misalnya c (kohesi), $\Phi$ (sudut geser), dan $\gamma$ (berat isi, tanah basah dan tanah kering). Satuan disesuaikan melalui konversi dalam standar SI (Satuan Internasional). Hanya dua satuan yang di konversi dari tabel 5 disesuaikan dengan kebutuhan input data ke program slope/w.

Tabel 5. Satuan Variabel

\begin{tabular}{cccc}
\hline $\begin{array}{c}\text { Nama } \\
\text { Variabel }\end{array}$ & $\begin{array}{c}\text { Satuan } \\
(\text { SI })\end{array}$ & $\begin{array}{c}\text { Faktor } \\
\text { Konversi }\end{array}$ & $\begin{array}{c}\text { Satuan } \\
\text { Konversi }\end{array}$ \\
\hline Berat isi $(\gamma)$ & $1 \mathrm{t} / \mathrm{m}^{3}$ & 9,807 & $9,807 \mathrm{kN} / \mathrm{m}^{3}$ \\
Kohesi $(\mathrm{c})$ & $1 \mathrm{~kg} / \mathrm{cm}^{2}$ & 98,07 & $98,07 \mathrm{Kpa}$ \\
\hline
\end{tabular}

Contoh Analisis Stabilitas Lereng Lokasi 1

Diketahui: Lereng $\quad=35^{\circ}$

Berat isi jenuh $(\gamma \mathrm{a}) \quad=18,92 \mathrm{KN} / \mathrm{m}^{3}$

Berat isi kering $(\gamma \mathrm{d}) \quad=14,87 \mathrm{KN} / \mathrm{m}^{3}$

Kohesi $(\mathrm{C}) \quad=13,68 \mathrm{kPa}$

Sudut geser $(\Phi) \quad=17,9^{\circ}$

Ditanyakan: Berapa Faktor Keamanan (Fs)?

Jawaban : 


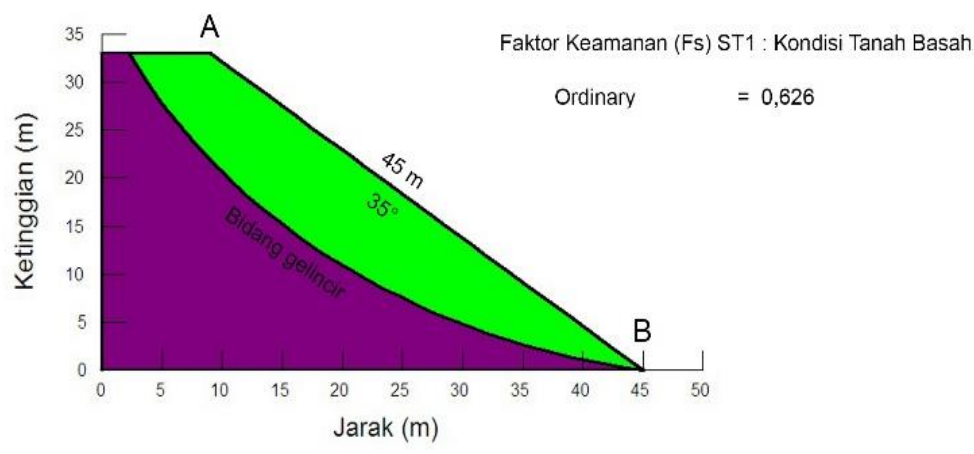

Gambar 8. Hasil penghitungan Program Slope/W di lokasi 1 dengan keadaan tanah basah

Dari hasil penghitungan diatas dengan nilai Faktor Keamanan (Fs) tanah basah Ordinary 0,626 artinya lereng

biasa/sering terjadi gerakan tanah atau lereng labil karena Fs kurang dari 1,25.

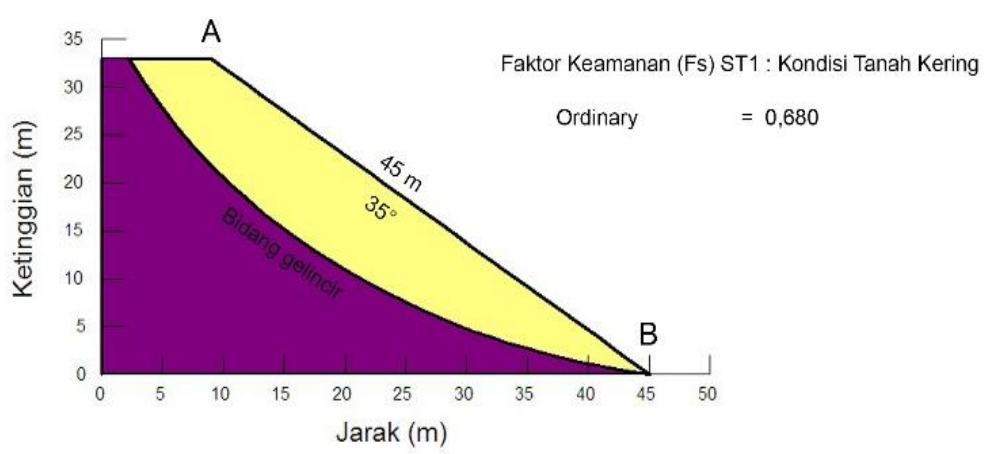

Gambar 9. Hasil penghitungan Program Slope/W di lokasi 1 dengan keadaan tanah kering

Dari hasil penghitungan diatas dengan nilai Faktor Keamanan (Fs) tanah kering ordinary $=0,680$ artinya lereng biasa/sering terjadi gerakan tanah atau lereng labil karena Fs kurang dari 1,25.

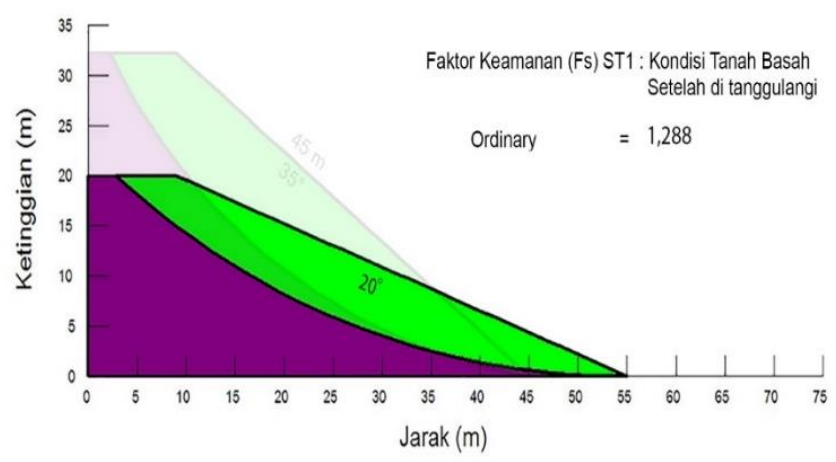

Gambar 10. Hasil penghitungan Program Slope/W di lokasi 1 setelah di lakukan pemotongan lereng 


\section{Rekomendasi Penanggulangan Gerakan Tanah}

1) Dari hasil penghitungan diatas didapatkan dengan nilai Faktor Keamanan (Fs) tanah basah 1,288 artinya lereng jarang terjadi gerakan tanah atau lereng stabil.

2) Adanya pemotongan lereng atas hingga $20^{\circ}$ dan mengurug di kaki lereng, untuk memperkecil kemiringan lereng.

Tabel 6. Hasil analisis stabilitas lereng lokasi 1

\section{Faktor}

\begin{tabular}{|c|c|c|c|}
\hline \multirow{2}{*}{$\begin{array}{c}\text { Kondisi } \\
\text { Tanah }\end{array}$} & \multicolumn{2}{|c|}{ Keamanan (Fs) } & \multirow{2}{*}{$\begin{array}{c}\text { Stabilitas } \\
\text { Lereng }\end{array}$} \\
\hline & Ordinary & $\begin{array}{c}\text { Rata- } \\
\text { rata }\end{array}$ & \\
\hline 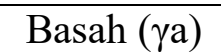 & 0,626 & 0,626 & Labil \\
\hline Kering $(\gamma \mathrm{d})$ & 0,680 & 0,680 & Labil \\
\hline $\begin{array}{c}\text { Basah } \\
\text { (Sudah di } \\
\text { tanggulangi) }\end{array}$ & 1,288 & 1,288 & Stabil \\
\hline
\end{tabular}

\section{Variasi Desain Lereng}

Hubungan antara faktor keamanan dengan sudut kemiringan lereng $\alpha$.

- Variasi $\alpha$ dengan $\mathrm{c}$ dan $\Phi$ tetap

Jika menggunakan data parameter yang sama tapi menggunakan kemiringan lereng yang berbeda maka akan diperoleh faktor keamanan pada lokasi 1 sebagai berikut.

Tabel 7. Hubungan antara Fs faktor keamanan dengan sudut $\alpha$

\begin{tabular}{ccc}
\hline $\boldsymbol{\alpha}^{\mathbf{o}}$ & Fs & Stabilitas Lereng \\
\hline 15 & 1,398 & Stabil \\
18 & 1,252 & \\
20 & 1,114 & Kritis \\
25 & 0,884 & \\
30 & 0,754 & Labil \\
35 & 0,680 & \\
\hline
\end{tabular}

Gambar 11 dibawah menunjukan pada kondisi sudut lereng lebih besar dari $20^{\circ}$, didapat bahwa nilai Fs (Faktor keamanan) 1,25 yg artinya Labil.

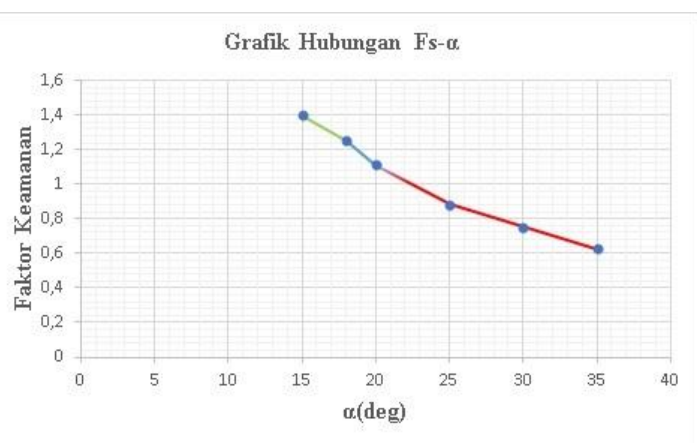

Gambar 11. Grafik hubungan antara Fs faktor keamanan dengan sudut $\alpha$ lokasi 1

\section{Hubungan antara faktor keamanan dengan} parameter geser $c$ dan $\Phi$

- Variasi c dengan $\alpha$ dan $\Phi$ tetap

Jika menggunakan parameter kemiringan lereng dan sudut geser yang telah diketahui, tapi menggunakan kohesi (c) yang berbeda diprogram komputer Slope/w, maka akan diperoleh nilai faktor keamanan (Fs) dapat dilihat pada table berikut.

\begin{tabular}{ccc}
\multicolumn{3}{c}{ Tabel 8. Hubungan Fs-c } \\
\hline $\begin{array}{c}\text { C } \\
\mathrm{kPa}\end{array}$ & Fs & $\begin{array}{c}\text { Stabilitas } \\
\text { Lereng }\end{array}$ \\
\hline 13 & 0,626 & \\
23 & 0,760 & \\
28 & 0,822 & Labil \\
37 & 0,931 & \\
46 & 1,034 & \\
49 & 1,068 & \\
52 & 1,103 & Kritis \\
60 & 1,194 & \\
66 & 1,263 & Stabil \\
\hline
\end{tabular}

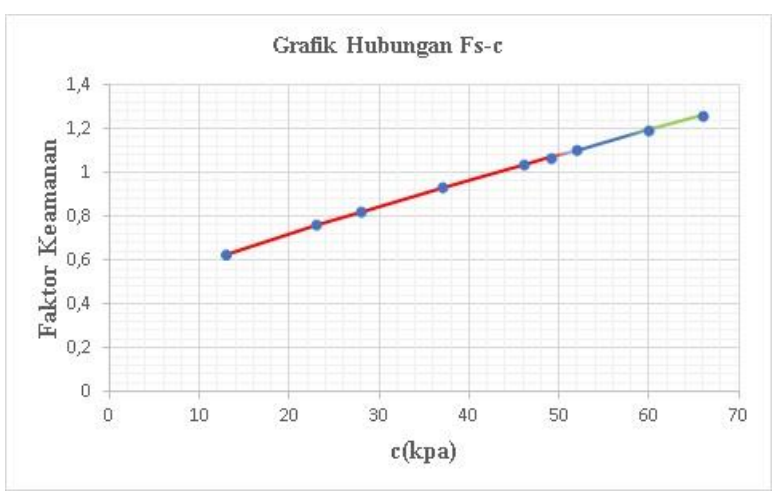

Gambar 12. Grafik hubungan antara Fs faktor keamanan dengan $\mathrm{c}$ kohesi 
Gambar 12 diatas menunjukan bahwa kohesi diatas 60kpa, didapat bahwa nilai Fs (Faktor keamanan) lebih dari 1,25 yg artinya stabil.

- Variasi $\Phi$ dengan $\alpha$ dan c tetap

Jika menggunakan parameter kemiringan lereng dan kohesi yang telah diketahui, tapi menggunakan sudut geser $(\Phi)$ yang berbeda diprogram komputer Slope/w, maka akan diperoleh nilai faktor keamanan (Fs) dapat dilihat pada table berikut.

Tabel 9. Hubungan Fs- $\Phi$

\begin{tabular}{ccc}
\hline $\boldsymbol{\Phi}^{\mathbf{0}}$ & Fs & $\begin{array}{c}\text { Stabilitas } \\
\text { Lereng }\end{array}$ \\
\hline 17 & 0,626 & \\
21 & 0,706 & \\
25 & 0,814 & Labil \\
30 & 0,979 & \\
34 & 1,069 & \\
36 & 1,133 & Kritis \\
40 & 1,271 & \\
42 & 1,346 & Stabil \\
\hline
\end{tabular}

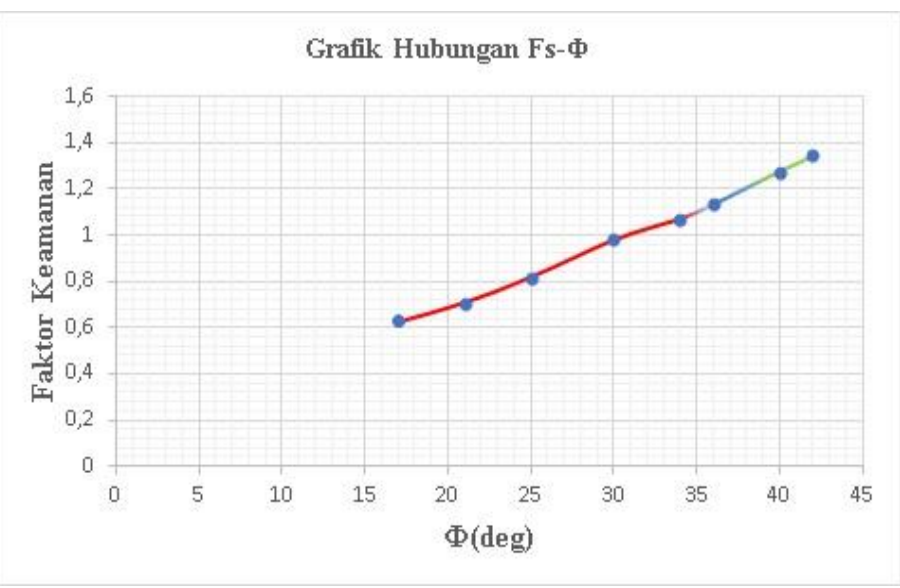

Gambar 13. Grafik hubungan antara Fs faktor keamanan dengan Sudut Geser $\Phi$ lokasi 1

Dengan cara yang sama maka analisis stabilitas lereng lokasi 2 dan 3 dapat ditentukan nilai dan hubungan faktor keamanannya.

\section{SIMPULAN}

1. Secara Administratif, lokasi penyelidikan terletak di daerah Cikalong Wetan, Kabupaten Bandung Barat, Provinsi Jawa Barat, secara geografis, lokasi penyelidikan terletak pada koordinat $6^{\circ}$ 41'30' - 6 44' 30' Lintang Selatan dan $107^{\circ} 26^{\prime} 30^{\prime}$ - $107^{\circ} 29^{\prime} 00^{\prime}$ ' Bujur Timur dengan luas $\pm 6 \mathrm{~km}^{2}$

2. Morfologi daerah penyelidikan terdiri dari 2 satuan morfologi, yaitu pada satuan morfologi perbukitan bergelombang curam dan satuan perbukitan landai. Gerakan tanah dilokasi penyelidikan umumnya pada zona kerentanan gerakan tanah menengah dan tinggi, pada tanah lanau-pasiran hasil dari pelapukan gunung api tua satuan breksi vulkanik.

3. Curah hujan bulanan daerah penyelidikan mempunyai curah hujan relatif tinggi. Menunjukan pada bulan kering dimulai bulan Juni sampai September yang kisaran curah hujan 10-90 mm/bulan, sedangkan bulan basah Oktober sampai Mei kisaran curah hujan 100-325 mm/bulan, hal ini pada bulan basah dapat memicu terjadinya gerakan tanah.

4. Tata guna lahan didaerah penyelidikan umumnya terdiri atas, kebun/perkebunan, sawah, ladang/tegalan, permukiman. Lokasi penyelidikan terletak perkebunan, sawah, ladang/tegalan.

5. Dari hasil analisis stabilitas lereng menggunakan program komputer Slope/w pada 3 lokasi dengan kemiringan dan panjang lereng yang berbeda, menunjukan bahwa lokasi 1 dan 2 pada kondisi tanah basah atau jenuh faktor keamanan (Fs) kurang dari 1,25 yang artinya lereng biasa/sering terjadi gerakan tanah atau lereng labil. Namun pada lokasi 3 menunjukan faktor keamanan (Fs) lebih dari 1,25 artinya lereng jarang terjadi gerakan tanah atau lereng stabil.

6. Sedangkan pada kondisi tanah kering di lokasi 1 dan 2 masih tetap faktor keamanan (Fs) kurang dari 1,25 yang artinya lereng biasa/sering terjadi gerakan tanah atau lereng labil, dikarenakan sudut kemiringan lereng yang sangat besar. Berbeda sebaliknya dengan lokasi 3 menunjukan faktor keamanan (Fs) lebih dari 1,25 artinya lereng jarang terjadi gerakan tanah atau lereng stabil.

7. Dari grafik hubungan Fs vs $\alpha$, didapat hubungan bahwa semakin kecil nilai sudut kemingan lereng maka semakin besar nilai faktor keamanan, itu artinya semakin 
landai lereng maka kondisinya semakin aman.

8. Dari grafik hubungan Fs vs c \& $\Phi$ didapat hubungan bahwa semakin besar nilai c \& $\Phi$ maka semakin besar nilai faktor keamanan yang didapat.

\section{REKOMENDASI}

1. Rekomendasi penanggulangan gerakan tanah di daerah penyelidikan pada kondisi yang tidak stabil. Maka perlu perlu diadakan perbaikan lereng, salah satunya mengurangi beban di puncak dengan melakukan pemotongan lereng agar memperkecil sudut kemiringan lereng, dan cara soil nailing dapat memperbesar gaya penahan dan memperkecil gaya pendorong. Tapi pembangunan soil nailing perlu mempertimbangkan aspek pembiayaan dan lingkungan.

2. Perlunya dibuat pengaturan saluran air permukaan agar pada saat hujan aliran air permukaan tidak langsung mengalir ke jalan dan meresap ke tebing lereng yang mengakibatkan lereng jadi jenuh air dan dapat memicu terjadinya gerakan tanah.

3. Perlu penataan permukiman agar tidak di tempatkan pada lereng perbukitan curam yang rawan gerakan tanah.

\section{DAFTAR PUSTAKA}

Bakorsurtanal. 1990. Peta Rupa Bumi Indonesia Lembar 1209-242, Cikalong Wetan.

Djaja, dkk. 2003. Hasil pemeriksaan Gerakan Tanah di Kp. Parakan Kadu, Ds. Wangunjaya, Kec. Cikalong Wetan, Kabupaten Bandung.

Fisher, R. V. 1966. Rocks Composed of Volcanic Fragments. Earth Science Reviews. International Magazine fo Geo-Scientist, Vol 1. page 287-298.

Gabriella, Violetta \& Pangemanan, Margaretha \& Turangan, A \& Sompie, Berty. 2014. Analisis Kestabilan Lereng Dengan Metode Fellenius (Studi Kasus: Kawasan Citraland). Jurnal Sipil Statik. 21. 37-46. Hidayat, R. 2018. Analisis Stabilitas Lereng pada Longsor Desa Caok, Purworejo, Jawa Tengah. JURNAL SUMBER DAYA AIR. $14 . \quad 63-74$. 10.32679/jsda.v14i1.195.

Hidayat, Rokhmat. 2018. Analisis Stabilitas Lereng pada Longsor Desa Caok, Purworejo, Jawa Tengah. JURNAL SUMBER DAYA AIR. 14. 63-74. 10.32679/jsda.v14i1.195.

Mustofa, A., dkk. 2017. Pengaruh Pelapukan Terhadap Sifat Mekanik Batuan Dan Tanah Residual Breksi Vulkanik Formasi Pitanak Di Kecamatan Karang Intan Kabupaten Banjar. Jurnal HIMASAPTA Vol 2, No 01. Universitas Lambung Mangkurat. https://doi.org/10.20527/jhs.v2i01.935

Pusat Vulkanologi dan Mitigasi Bencana Geologi. 2014. Peta Zona Kerentanan Gerakan Tanah, Kabupaten Bandung Barat, Jawa Barat. Badan Geologi Kementerian ESDM.

Rohman S. 2016. Analisis Stabilitas Lereng Pada Pelapukan Batuan Vulkanik di Karangtanjung, Cililin, Kabupaten Bandung Barat, Jawa Barat. Tugas Akhir.Tidak diterbitkan.

Somantri, A. T. 1999. Geomorfologi Umum. Bandung: Alumni Press.

Sudjatmiko, dkk. 1972. Peta Geologi Lembar Cianjur, Jawa Barat. Badan Geologi Kementerian ESDM.

Sutisna, J. dan Wahyono. 2013. Peta Geologi Teknik Lembar Jawa bagian Barat. Badan Geologi Kementerian ESDM, skala 1:500.000, 1 lembar.

van Bemmelen, R.W. 1970. The Geology of Indonesia Vol. IA General Geology of Indonesia and Adjacent Archipleagoes. Government Printing Office, The Hague.

van Zuidam, R.A. 1983. Guide to Geomorphologic-Aerial Photographic Interpretation and Mapping. ITC, Enscede, Netherland. 